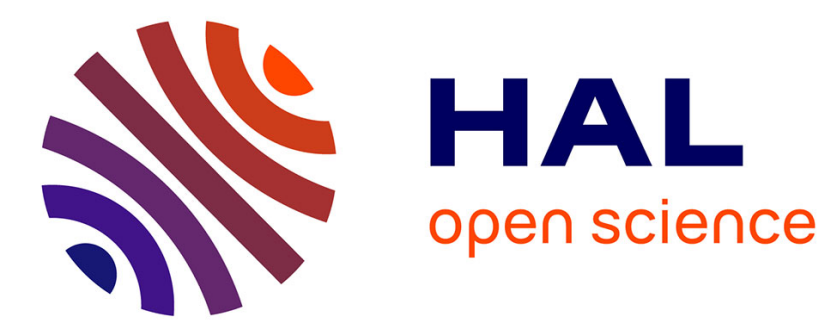

\title{
Design of an assembly for nonlinear vibration reduction
} Pauline Butaud, Gael Chevallier

\section{To cite this version:}

Pauline Butaud, Gael Chevallier. Design of an assembly for nonlinear vibration reduction. Conference and Exposition on Structural Dynamics, Jan 2017, Garden Grove, CA, United States. hal-02131346

\section{HAL Id: hal-02131346 \\ https://hal.science/hal-02131346}

Submitted on 16 May 2019

HAL is a multi-disciplinary open access archive for the deposit and dissemination of scientific research documents, whether they are published or not. The documents may come from teaching and research institutions in France or abroad, or from public or private research centers.
L'archive ouverte pluridisciplinaire HAL, est destinée au dépôt et à la diffusion de documents scientifiques de niveau recherche, publiés ou non, émanant des établissements d'enseignement et de recherche français ou étrangers, des laboratoires publics ou privés. 


\title{
Design of an Assembly for Nonlinear Vibration Reduction
}

\author{
P. Butaud ${ }^{1}$, G. Chevallier ${ }^{1}$ \\ ${ }^{1}$ Univ. Bourgogne Franche-Comté, FEMTO-ST Institute, CNRS/UFC/ENSMM/UTBM \\ Department of Applied Mechanics, 25000 BESANCON-FR
}

\begin{abstract}
The lightness of the space and aerospace structures causes their vulnerability to vibrations. The cold temperatures do not allow using polymer materials. Active and semi-active control using piezos embedded on the structure can be used efficiently instead of polymers but they induce energy consumption. Friction damping is less efficient but it does not depend on temperature and it is energetically passive. Unfortunately its efficiency depends on the vibration amplitude as well as on the tightening force. The damping is very low for the lowest amplitudes and the largest tightening loads and increase up to an optimal value. This optimum damping is adjustable thanks to the tightening force. The purpose of our work is to evaluate the efficiency of the control of the tightening force in bolted joints to reduce the vibration of the assembled structure. In the first part, we present a original setup and a very detailed design of experiments that highlights the optimal sets of parameter in order to get a good control of the vibrations according to the frequency and the magnitude of the load. To conclude, we propose to share experimental data with the attendees for further discussions.
\end{abstract}

keywords: assembly, lapjoint, nonlinear, experimental, dynamic.

\section{Introduction}

The modeling and the prediction of vibration damping remains a great challenge because the physical phenomena involved in energy dissipation are not very well known. The damping might be induced through several common ways such as viscoelastic materials, pressure loss in fluids or solid friction. The latter remains badly modeled, whereas the joints, such as welded points, bolted joints or rivets, are widely used to link the parts of the mechanisms and the structures.

Among all the studies that focus on friction-damping, it is commonplace to separate the works that highlight energy dissipations coming from macro-sliding, and micro-sliding. In the first category, the damping is due to long-scale friction zones, see Berthillier et al.[1] or Poudou et al. [2] for instance. In this case, simulations and tests are easy to perform because the contact region is generally well-localized and the slipping occurs all over the contact area. In the second case, the damping comes from partial sliding between the parts. Thus the effective contact region is generally badly known and stick-slipseparation in the interfaces is commonplace. It was shown experimentally by many authors (Goodman et al. [3], Beards et al.[4], Pian [5], Ungar [6]) that, in turn, the modal damping and the eigenfrequencies are strongly dependent to the vibration amplitudes. This is due to the pressure and the shear stress variations. This leads to difficulties in modelling this case, see Festjens et al. [7] and Caignot et al. [8]. In simulations, geometrical defects and loading trajectories have to be carefully taken into account. To avoid this difficulty, it is also possible to measure and identify meta-models, see Festjens et al. [9], on specifically designed test-benchs. Several testing devices have been designed in order to achieve this goal Fig.1. The advantages of most of the experimental setups, according to their design properties and their experimental process, were exposed in Dion et al. [10]. Special attention has been payed to the coupling between tangential and normal loads in the joints because this coupling makes the experiments quite hard to perform, as the limit of sliding is depending on the normal load dynamics. Each of these experimental configurations had been tested with specific excitation devices and excitation signals. There are several experimental ways to highlight non-linear effects such as amplitude-dependent eigenfrequencies and damping, which are very commonplace for friction dampers. Many works are based on steady-state analysis in order to build Frequency Response Functions (FRF), $[11,4,12]$ to estimate the Energy Loss (EL), through the frequency bandwidth or the quality factor of each modes. EL can also be estimated through quasi-static analysis $[11,13,3]$. In this case, the objective is to build energy ratios for various loading trajectories. This experimental procedure is very close to the procedure performed with Dynamic Mechanical Analyzer (DMA) for viscoelastic properties identification. Transient analysis can also be performed: the classical approach is to excite the structure with an impact hammer [14]. A more original approach is to obtain free-decay response by disconnecting the sine-excitation device to the structure since a steady-state response very close to the modal response was obtained [15], [16]. This procedure is called stop-sine. It allows to get the so-called backbones of the system; that is to say, the amplitude-dependence of the natural frequency and the modal damping.

The new setup presented in this paper is composed of two thin beams linked by three bolted joints. Contact patches have been added to each contact area in order to ensure the contact localization. This make this experience robust compared to 

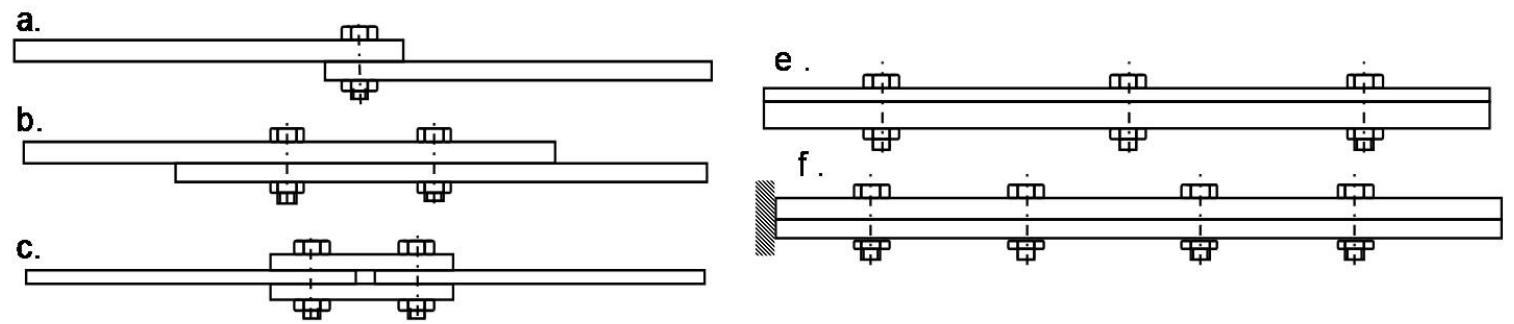

Fig. 1: Exemples of testing devices develloped to highlight friction induced damping in joints. a. Beam assembly with a single bolted joint from Ahmadian et al. [11]- b. Beam assembly with two bolted joints from Metherell et al [13] or Esteban et al. [12]-c. Beam assembly symetrically screwed with two bolted joints from Song et al. [16] - e. beam assembly with distributed bolted joints in free conditions from Heller et al [15, 18]- f. beam assembly with distributed bolted joints in clamped-free conditions from Goodman et al [3], Nanda et al.[19, 20].

previous ones. Among the three bolted connexions, one is dedicated to the stiffness function, the two others are dedicated to energy dissipation. Thus, this new setup is a functionalized assembly that allows to manage these two important parameters of a dynamic device. Few years ago, Sandia Institute proposed a benchmark that involves two thick beams also linked by three bolted joints [21]. Compared with Sandia's one, this new setup aims to complete the knowledge on assembly dynamics with a new academic configuration. The paper is organized as follow: we first present the setup, then we present results under random and harmonic excitation.

\section{Experimental setup}

The benchmark designed in this work is an assembly of two beams with the following dimensions $200 \times 30 \times 1.7 \mathrm{~mm}$. The beams are linked together by three M4 screws spaced of $15 \mathrm{~mm}$. In order to avoid uncertainties on the contact area, there are contact patches under each screw with an extra thickness of $0.3 \mathrm{~mm}$ and a square of $12 \mathrm{~mm}^{2}$ for external screws and $18 \mathrm{~mm}^{2}$ for the central screw (Figure 2(a)). A washer is placed under each screw and nut each. The tightness applied on the external screws is $10 \mathrm{cNm}, 40 \mathrm{cNm}$ or $80 \mathrm{cNm}$, to observe its influence on the structure response. The tightness of the central screw is constant during the tests, this screw ensures the stiffness of the assembly, the tightening torque applied is $80 \mathrm{cNm}$. The tightening torque is obtained with a torque wrench and is checked during the experiment thanks to the instrumentation of the screw (strain gauges in the screw head).

The structure is clamped on one side (Figure 2(b)). In order to be as close as possible to a perfect clamp, a length $30 \mathrm{~mm}$ is screwed into a heavy steel block. The assembly is excited next to the clamp by a electromagnetic shaker model K2004E01 from the modalshop. Two excitations signals have been used: a frequency-controlled white noise between $20 \mathrm{~Hz}$ and $2000 \mathrm{~Hz}$ and a step-sine varying between $900 \mathrm{~Hz}$ and $1100 \mathrm{~Hz}$. In order to highlight the non-linear behavior of the structure, the excitation amplitude varies between [100-500] $\mathrm{mV}$ in white noise and [10-500] $\mathrm{mV}$ for harmonic test.

The measurement are made using PSV-500 scanning laser 3D vibrometer from Polytec, its working distance is between $125 \mathrm{~mm}$ and $100 \mathrm{~m}$, its minimum resolution is of 10 nanometers per second per square root of frequency. The structure is scanned on 118 points during the random excitation and on 92 points for the harmonic tests. The acquisition is repeated six times and averaged in order to build the H1 estimator of the Frequency Response Function between the excitation signal and the measured velocity. The results presented in next sections are the FRF RMS velocity.
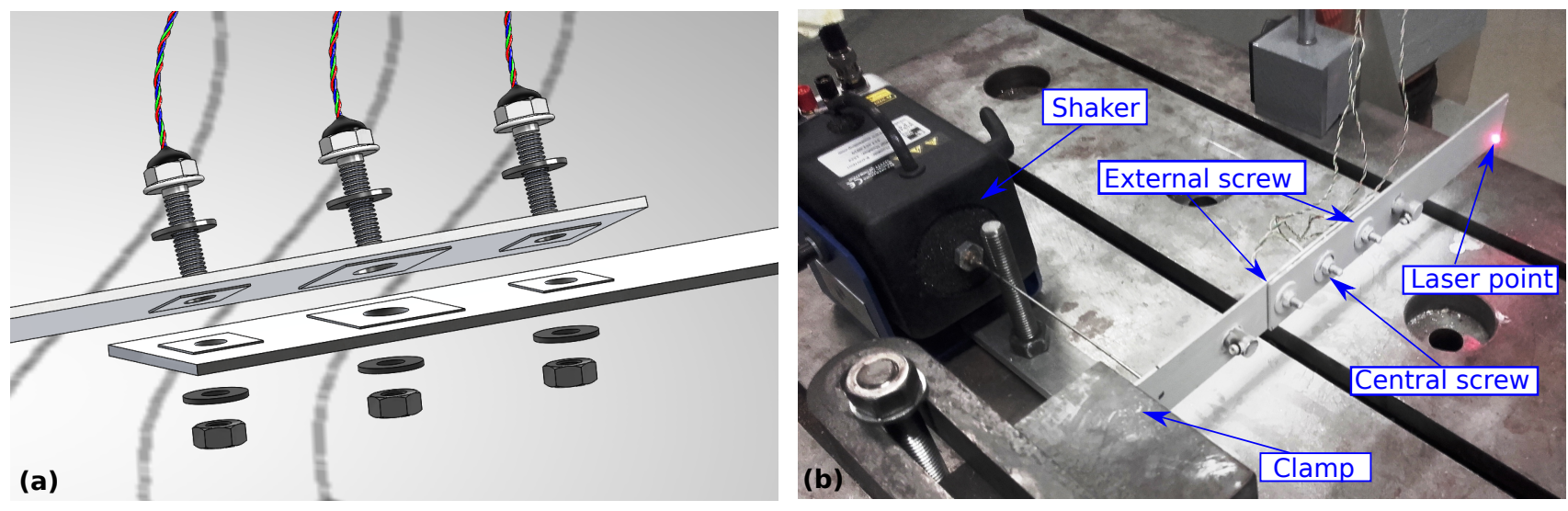

Fig. 2: (a) Lapjoint CAO. (b) Experimental setup. 


\section{Results}

\subsection{Random excitation results}

The first analysis is conducted to observe the influence of the excitation amplitude. The three tightening torques are tested, the result at $10 \mathrm{cNm}$ is presented on the Figure 3). For this degree of tightness, as for the others, a nonlinear behavior is noticed: the increase of the excitation amplitude induces a shift of the resonance frequency near the low frequencies and leads to an increase of the damping.

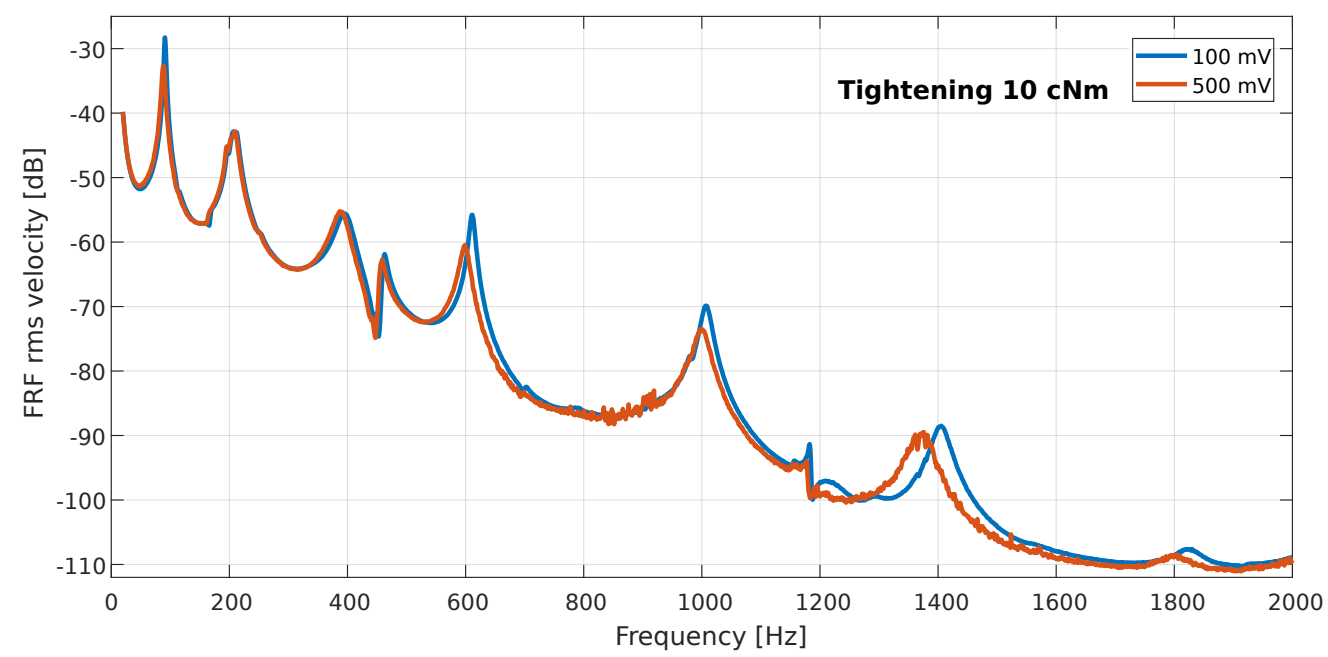

Fig. 3: Influence of the excitation amplitude, at $10 \mathrm{cNm}$ of tightness degree, for a random excitation of white noise type between [20-2000] Hz.

The second analysis is conducted to observe the influence of the tightening torque, only the external screws are impacted. This test is done for two excitation amplitudes $(100 \mathrm{mV}$ and $500 \mathrm{mV})$. The FRF RMS velocity for the three tightness is presented at $100 \mathrm{mV}$ on the Figure 4. For this excitation amplitude, as for the other, a nonlinear behavior is observed: the decrease of the tightness induces a shift of the resonance frequency near the low frequencies and leads to a decrease of the damping.

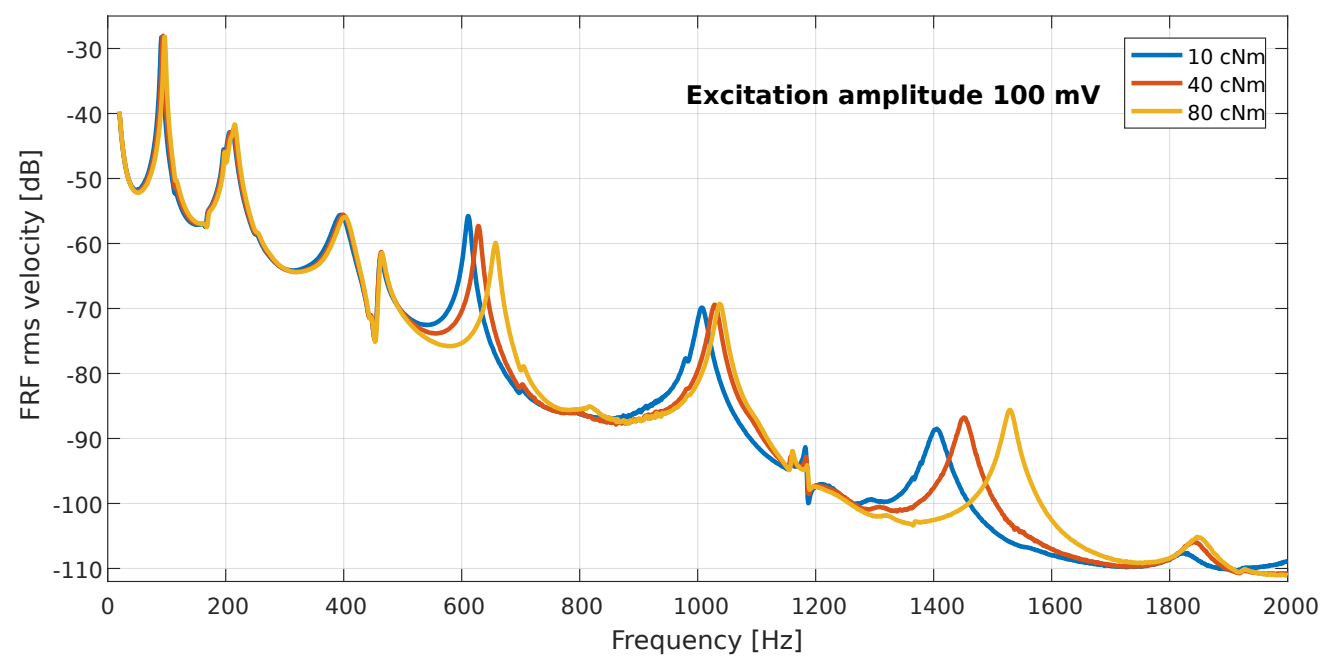

Fig. 4: Influence of the tightening torque, at $100 \mathrm{mV}$ for excitation amplitude, for a random excitation of white noise type between [20-2000] Hz. 


\subsection{Harmonic results}

The Figure 5 shows the influence of the excitation amplitude on the structure behavior between $900 \mathrm{~Hz}$ and $1100 \mathrm{~Hz}$. The curves presented here are obtained for a degree of tightness of $80 \mathrm{cNm}$ and for 5 excitation amplitudes between $10 \mathrm{mV}$ and $500 \mathrm{mV}$. It can be noticed that more the excitation is important, more the resonance is damped. The effect of the excitation amplitude is quite impressive. The mode almost disappears in this observed frequency window. From $100 \mathrm{mV}$, the non-linearity of the peak is clear, and from $250 \mathrm{mV}$, the higher order mode is observed.

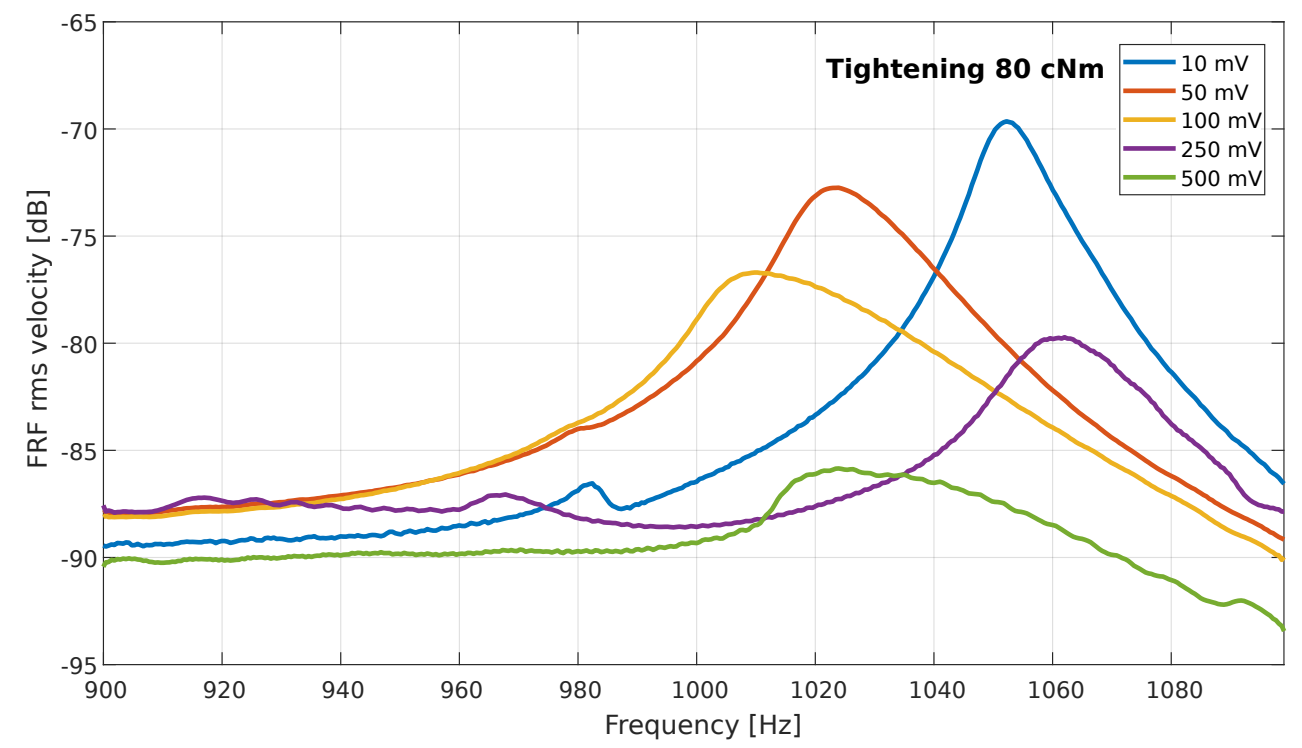

Fig. 5: Influence of the excitation amplitude for harmonic excitation between [900-1000] $\mathrm{Hz}$ and for one tightening torque of $80 \mathrm{cNm}$.

In a second time, the excitation amplitude is fixed at $100 \mathrm{mV}$ and the tightening torque varies between $10 \mathrm{cNm}$ and $80 \mathrm{cNm}$. The FRF RMS velocity observed is given in the Figure 6 . The results are very interesting, with the loosening of the screws the damping is drastically increased. The wavelets observed comes from a chirp experimental issue but do not question the conclusions.

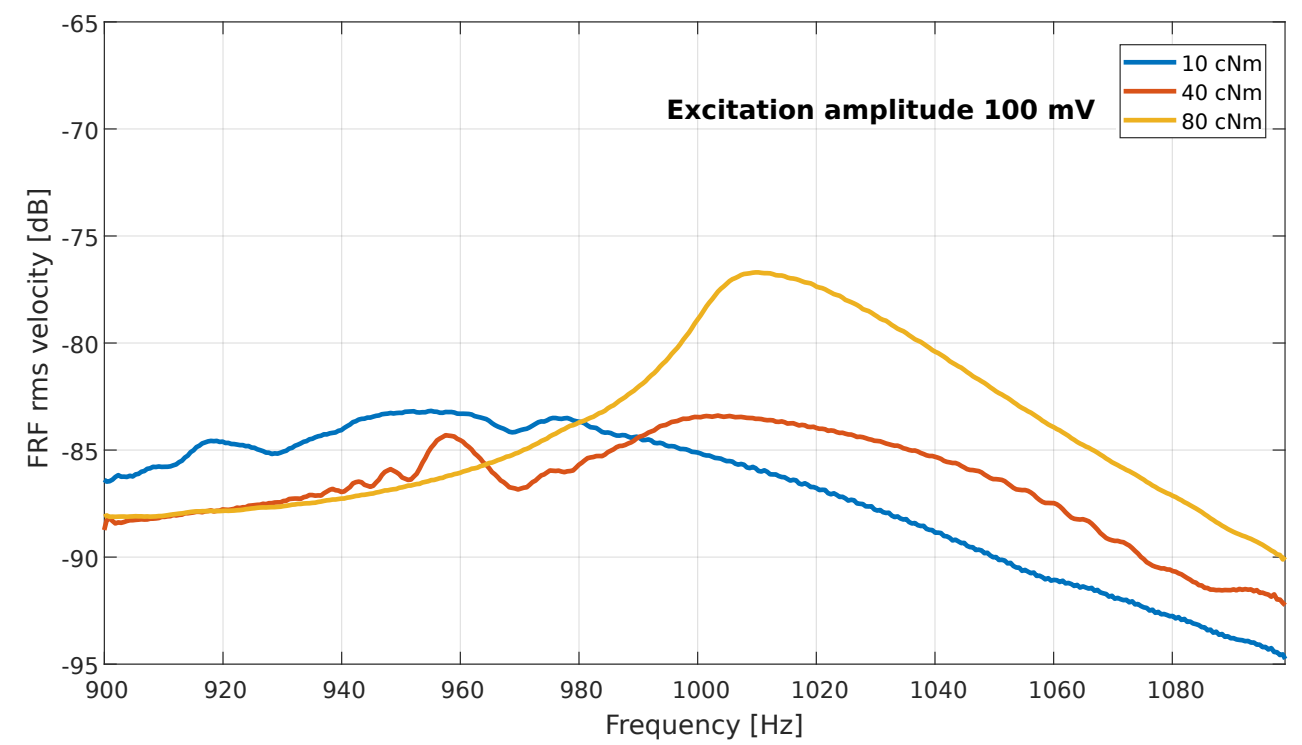

Fig. 6: Influence of the tightening, sine excitation [900-1000] Hz. 


\section{Conclusions}

This work aims to provide detailed datas to anyone who want to improve its simulation tools. All the experimental datas can be asked to the authors and will be sent in a "unv" file. Numerical datas, such as meshes and geometry, material properties, loadings amplitude can also be sent. Moreover, this wrk highlight the fact that this kind of functionnalized connexion can be used for vibration control as it can be used to get damping and to tune the natural frequencies.

\section{Acknowledgments}

The authors would like to acknowledge the "Fond Interministeriel Unique" that funds the project CLIMA and the "BourseOral UNESCO Pour les Femmes et la Science" that encourage women to make sciences.

\section{References}

[1] M. Berthillier, C. Dupont, R. Mondal, and Barrau. Blades forced response analysis with friction dampers. Transactions of the American Society of Mechanical Engineers, 120:468-474, 1998.

[2] O Poudou and C Pierre. Blades forced response analysis with friction dampers. PhD thesis, University of Michigan, 2007.

[3] LE Goodman and JH Klumpp. Analysis of slip damping with reference to turbine blade vibration. ASME Applied Mechanics Division, 23(3):421$429,1956$.

[4] CF Beards and JL Williams. The damping of structural vibration by rotational slip in joints. Journal of Sound and Vibration, 53(3):333-340, 1977.

[5] THH Pian. Structural damping of a simple built-up beam with riveted joints in bending. ASME Journal of Applied Mechanics, 24:35-38, 1957.

[6] EE Ungar. The status of engineering knowledge concerning the damping of built-up structures. Journal of Sound and Vibration, 26(1):141-154, 1973.

[7] Hugo Festjens, Gal Chevallier, and Jean-luc Dion. A numerical tool for the design of assembled structures under dynamic loads. International Journal of Mechanical Sciences, 75:170-177, October 2013.

[8] A. Caignot, P. Ladeveze, D. Neron, and J.-F. Durand. Virtual testing for the prediction of damping in joints. Engineering Computations, 27(5):621$644,2010$.

[9] H. Festjens, G. Chevallier, and J.L. Dion. Nonlinear model order reduction of jointed structures for dynamic analysis. Journal of Sound and Vibration, 333(7):2100-2113, March 2014

[10] Jean-Luc Dion, Gaël Chevallier, and Nicolas Peyret. Improvement of measurement techniques for damping induced by micro-sliding. Mechanical Systems and Signal Processing, 34(1-2):106-115, 2012.

[11] Hamid Ahmadian and Hassan Jalali. Identification of bolted lap joints parameters in assembled structures. Mechanical Systems and Signal Processing, 21(2):1041-1050, 2007.

[12] Jaime Esteban and Craig A Rogers. Energy dissipation through joints: theory and experiments. Computers \& Structures, 75(4):347-359, 2000.

[13] Alexander F Metherell and SV Diller. Instantaneous energy dissipation rate in a lap joint?uniform clamping pressure. Journal of Applied Mechanics, 35(1):123-128, 1968.

[14] Y. Ren and C Beards. Identification of joint properties of a structure using frf data. Journal of Sound and Vibration, 186(4):567-587, 1995.

[15] L Heller. Damping in assemblies structures. PhD thesis, Universite de Franche-Comte, 2005.

[16] Y Song. Simulation of dynamics of beam structures with bolted joints using adjusted iwan beam elements. Journal of Sound and Vibration, 273(1-2):249-276, 2004

[17] Hugh Goyder, Philip Ind, and Daniel Brown. Development of a method for measuring damping in bolted joints. In Proc. IDTEC ASME, 2009.

[18] Ludek Heller, Emmanuel Foltete, and Jean Piranda. Experimental identification of nonlinear dynamic properties of built-up structures. Journal of Sound and Vibration, 327(1):183-196, 2009.

[19] B.K. Nanda and A.K Behera. Study on damping in layered and jointed structures with uniform pressure distribution at the interfaces. Journal of Sound and Vibration, 226(4):607-624, 1999.

[20] B.K. Nanda. Study of the effect of bolt diameter and washer on damping in layered and jointed structures. Journal of Sound and Vibration, 290(3-5):1286-1314, 2006

[21] Loic Salles, Christian Swacek, Robert Michael Lacayo, Pascal Reuss, MRW Brake, and CW Schwingshackl. Numerical round robin for prediction of dissipation in lap joints. In Nonlinear Dynamics, Volume 1, pages 53-64. Springer, 2016. 